\title{
Correction to: Partitioning of adipose lipid metabolism by altered expression and function of PPAR isoforms after bariatric surgery
}

\author{
C. Jahansouz ${ }^{1} \cdot$ H. Xu ${ }^{2} \cdot$ A. V. Hertzel ${ }^{2} \cdot$ S. Kizy ${ }^{1} \cdot$ K. A. Steen ${ }^{2} \cdot$ R. Foncea ${ }^{2} \cdot$ F. J. Serrot ${ }^{1} \cdot$ N. Kvalheim ${ }^{2} \cdot$ G. Luthra $^{3} \cdot$ \\ K. Ewing ${ }^{4} \cdot$ D. B. Leslie ${ }^{1} \cdot$ S. Ikramuddin ${ }^{1} \cdot$ D. A. Bernlohr ${ }^{2}$
}

Published online: 6 August 2019

(c) Macmillan Publishers Limited, part of Springer Nature 2019

\section{Correction to: International Journal of Obesity} https://doi.org/10.1038/ijo.2017.197
Following the publication of this paper the authors discovered that Fig. 1f was a duplicate of Fig. 1g. The corrected version of the figure is published below with Fig. If amended.

S. Ikramuddin

Ikram001@umn.edu

$\triangle$ D. A. Bernlohr

Bern1001@umn.edu

1 Department of Surgery, University of Minnesota, Minneapolis, MN, USA

2 Department of Biochemistry, Molecular Biology and Biophysics, University of Minnesota, Minneapolis, MN, USA

3 Park Nicollet Bariatric Surgery Center, St. Louis Park, MN, USA

4 CentraCare Bariatric Center, St. Cloud, MN, USA 
Fig. 1

f
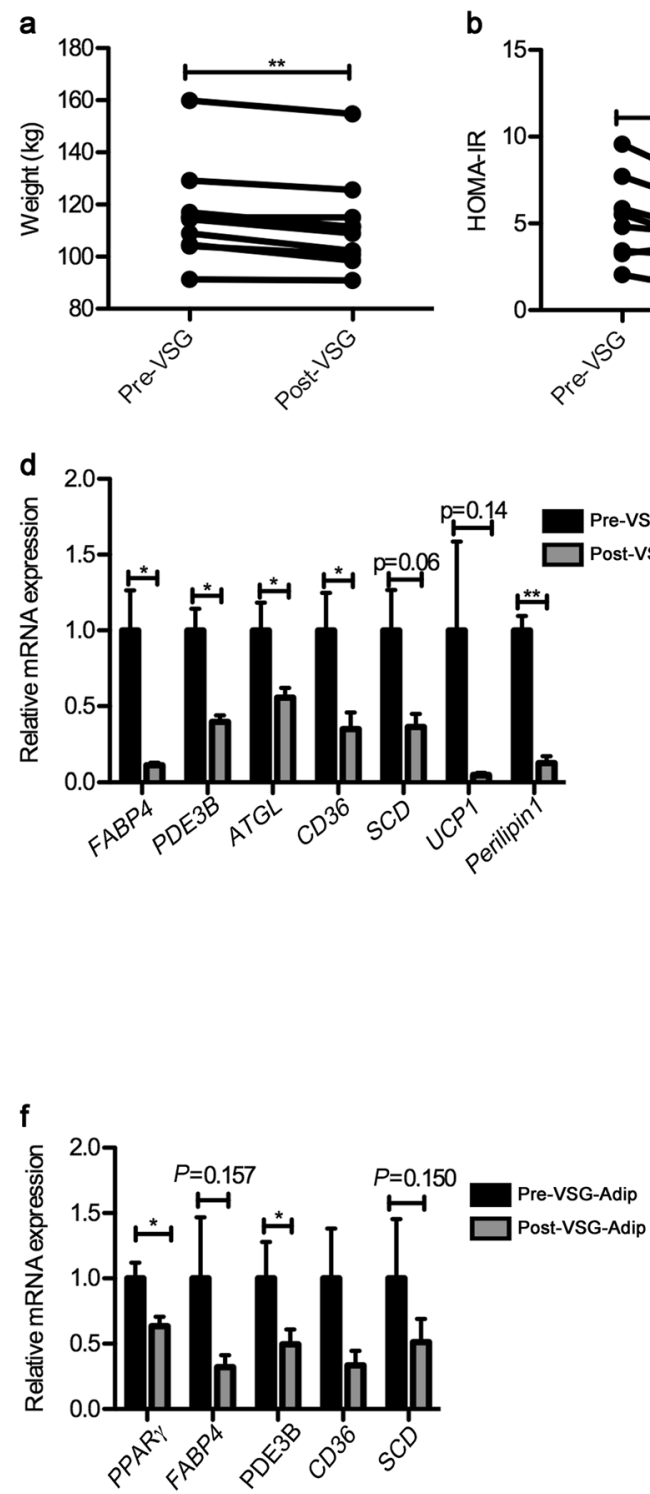
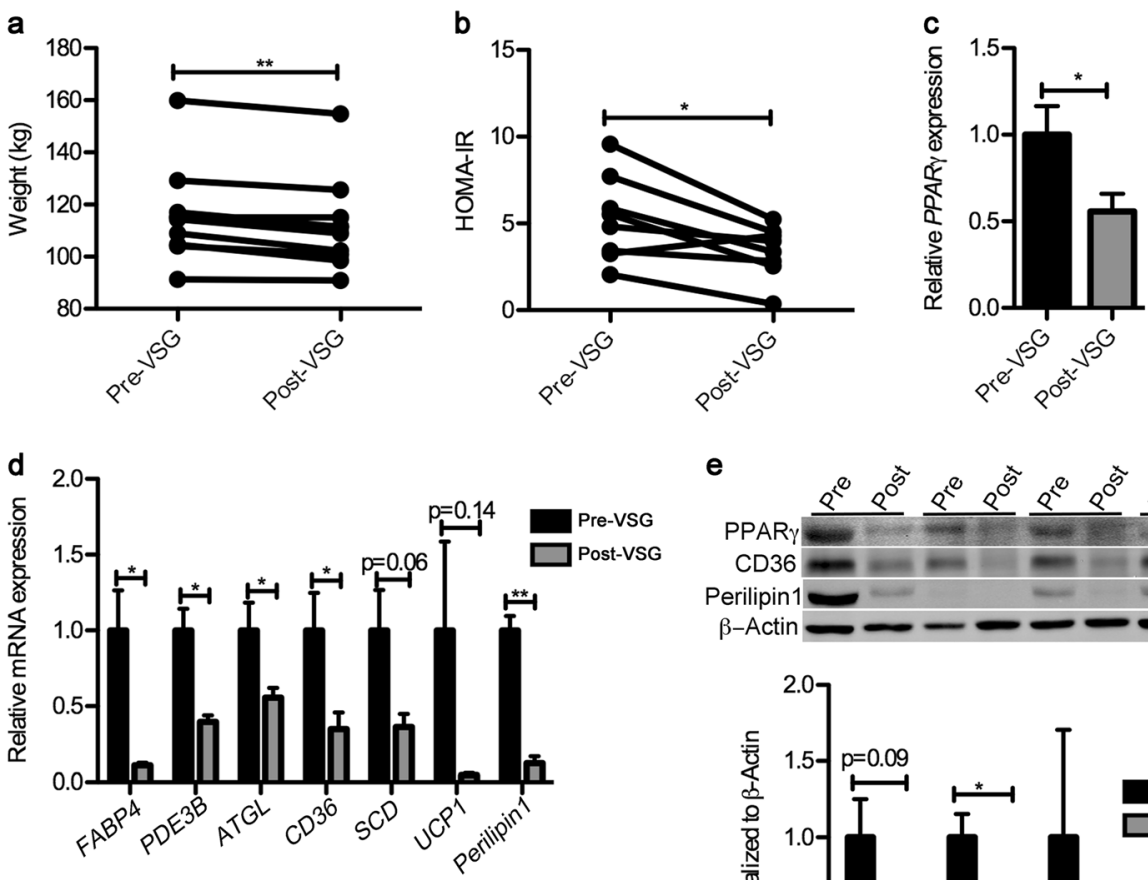

e
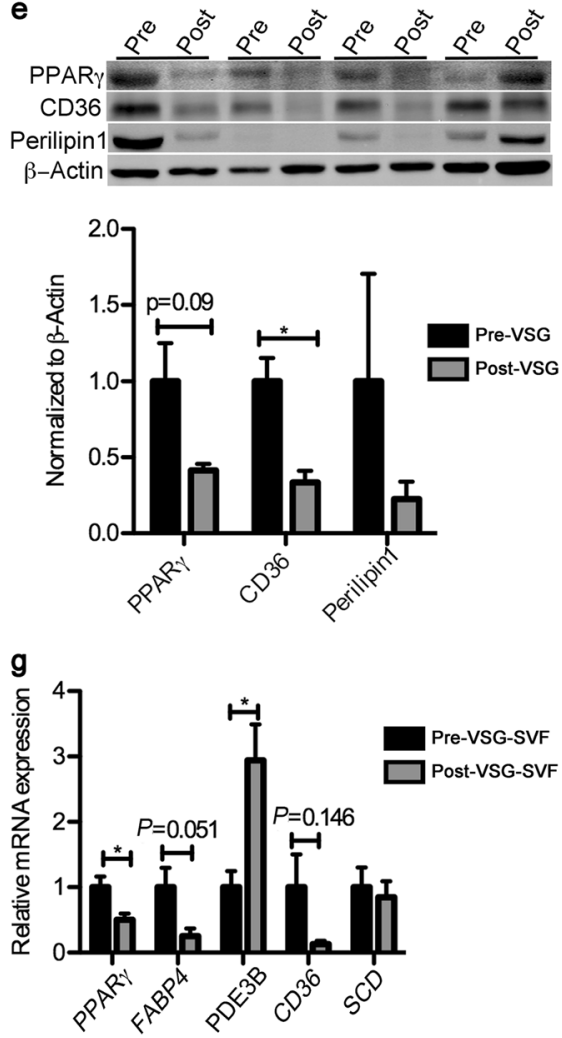